\title{
A Cross-Cultural Study on the Effect of Group Discussion in AHP-Group Decision Making for a Car Purchase
}

Pilsung Choe ${ }^{*} \cdot$ Wen $\mathrm{Zhu}^{* *}$

*Department of Industrial Engineering, Tsinghua University, Beijing, P.R. China ${ }^{* *}$ Department of Management and Science, School of Economics and Management, Tsinghua University, Beijing, P.R. China

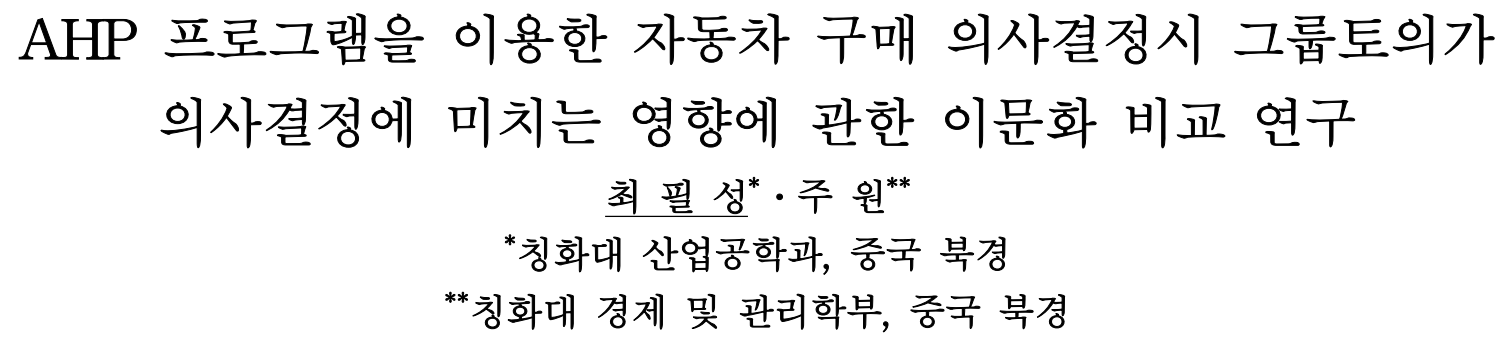

\begin{abstract}
In the trend toward globalization, cross-cultural teams in organizations are becoming more and more common. In particular, the influence of China and Western Europe on the global economy is getting increased.

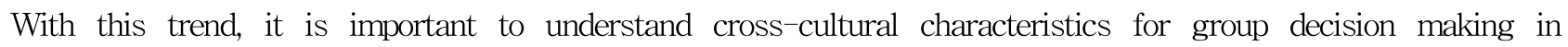
managerial environments. This study aims at analyzing cross-cultural differences between China and Western Europe in light of the effect of group discussion in group decision making. An experiment simulating a decision of a car purchase was conducted. A total of 48 subjects (24 Chinese and 24 Western Europeans) assigned in decision groups were asked to judge relative importance ratios of nine factors affecting their purchase decisions using the AHP program developed for the experiment. Three dependent variables (consistency, satisfaction, and consensus) were measured. Chinese were slightly more consistent than Western Europeans in discussion-involved group decision making. In terms of decision satisfaction, Western Europeans were more satisfied with discussion-included decisions than discussion-excluded decisions. Chinese, on the contrary, did not show a significant difference. There was no significant difference between two cultures in decision consensus.

Keywords : Group decisions, Group discussion, Cross-cultural difference, AHP, China, Western Europe
\end{abstract}

\section{Introduction}

People often engage in group decision making[8].

Diverse group decision-making methods such as brainstorming, buzz group analysis, nominal group technique, and Delphi technique are widely used to improve decision quality[17].

† Corresponding Author: Pilsung Choe, $\mathrm{PhD}$ (Associate Professor), Department of Industrial Engineering, Tsinghua University, Beijing, 100084, P.R.China

Tel.: 86-10-62796593 E-mail: pchoe@tsinghua.edu.cn; pschoe@gmail.com

Received November 22, 2012; Revision Received March 5, 2013; Accepted March 5, 2013. 
Group decision making has the advantages of sharing experiences and perspectives of individuals, being possibly more creative and effective, and sometimes achieving results beyond the capabilities of individuals[4, 19, 31]. Besides, group decision making is often more enjoyable and easier to implement[4]. Previous research has shown the advantages of group decision making[10, 29]. However, group decision making also has some disadvantages. The representative weaknesses of group decision making are groupthink[12] and group polarization[24]. In addition, groups rarely outperform their best member[22]. Sometimes, they don't come to a final decision after long discussion. Group decision making is becoming an important working process in international companies having diverse cultures of employees in the age of globalization.

As Chinese market recently receives more and more attention, the importance of cross-cultural group decision making is increasing as a key success factor of a business in China. As Western Europe in particular has many global companies having their business presence in China, such as BMW (Germany), Mercedes-Benz (Germany), Carrefour (France), and Zara (Spain), understanding Sino-Western European cultural differences in group decision making is considered to be also very important. In this regard, this research investigates Sino-Western European cultural differences in the light of the effect of group discussion in group decision making. The analytical hierarchy process (AHP) was used for the experiment of a group decision making for a car purchase as a case study.

\section{Related Work and Hypotheses}

\subsection{Analytical hierarchy process}

In this study, the analytical hierarchy process (AHP)[27] was used for the experiment of a group decision making for a car purchase. Usually, there are four ways to make the priorities for the AHP: (1) consensus, (2) vote or compromise, (3) geometric mean of the individuals' judgment, and (4) weighted arithmetic mean[6, 15, 26]. Consensus refers to achievement of agreement of group participants in making judgments. If consensus cannot be obtained, the group may choose a vote or a compromise of the individual judgments, or may use a geometric mean of the individuals' judgments. These three ways use judgments of individuals while the last one use the priorities derived from the judgments[6, 26]. Consensus, geometric mean of the individuals' judgment, and weighted arithmetic mean were used in this study.

The AHP has been extensively studied in many applications. Chen and Huang adopted the AHP method to obtain professional's opinions on the selection strategy of high-tech industries[5]. Byun used the AHP for a decision on a car purchase[2]. He structured the problem with eight main criteria (exterior, convenience, performance, safety, economic aspect, dealer, and warranty) and 39 sub-criteria. He gave $1 / \mathrm{CR}$ as group's weight in order to assign higher weights for higher consistent persons. Tam applied the AHP for selecting suppliers in telecommunication system[30]. Forgionne and Kohli used AHP to make assessment of decision technology system journal quality[7]. Liberatore and Nydick used the AHP for a decision on higher education[18]. As for the group discussion effect based on the AHP, Melon et al. examined the difference between a decision based on face-to-face discussion (FTF) and a computer-mediated (CM) decision[21]. The result showed that FTF method had better performance and satisfaction.

\subsection{Characteristics of group decisions}

A group decision making differs in some respects from an individual decision making. Some research is focused on how the group decision result is derived and how the advice is combined[9, 16]. The typical phenomena in group decision making different from individual decision making are groupthink and group polarization. Groupthink is "a mode of thinking that people engage in when they are deeply involved in a cohesive in-group, when members' strivings for unanimity override their motivation to realistically appraise alternative courses of action"[12]. Group 
polarization is the tendency of a group to make decisions that are more extreme than the initial opinions of its members[24]. In addition to these two phenomena, group consensus is known to change individual attitudes and opinions. Consensus does not mean that all group members have one mindset. Consensus is a process to reach a best decision for a group. Consensus-driven decisions are the result of the following practices of groupthink[13].

Group decision making influenced by the aforementioned characteristics has been often researched in terms of decision accuracy, decision satisfaction, and consensus in comparison with individual decision making[1, 10, 14, 16, 28, 29].

\subsection{Culture and decision making}

Cultures influence decision makings[3, 25, 32].

However, the effect of group discussion in group decision making in light of Sino-Western European cultural differences has not been actively researched.

As a result of the differences in geographic environment, historical background, and development course between China and Western Europe, Western European culture and Chinese culture have distinct characteristics[33]. Hofstede classified national cultures with five dimensions[11]: (1) Power distance - from small to large (PDI), (2) collectivism versus individualism (IDV), (3) femininity versus masculinity (MAS), (4) uncertainty avoidance from small to large (UAI), and (5) long-term versus short-term orientation (LTO). Table 1 shows scores of China and Western Europe in Hofstede's five cultural dimensions - PDI, IDV, MAS, UAI, and LTO[11]. As shown in the table, some scores are missing in Hofstede's research. Although Western Europe's scores disperse, they are clearly distinguished from China's scores within certain ranges in all dimensions except for the MAS. China has a higher score than any Western European country in the PDI and the LTO. On the contrary, China has a lower score than any Western European country in the IDV and the UAI. In the MAS, some Western European countries (Belgium, France, Greece, Luxemburg, Netherlands, Portugal, and Spain) have lower scores than China, and others not.
Table 1. Hofstede's scores

\begin{tabular}{cccccc}
\hline & PDI & IDV & MAS & UAI & LTO \\
\hline China & 80 & 20 & 66 & 30 & 118 \\
W. Europe's & 45 & 63 & 55 & 73 & 34 \\
Average. & & & & & \\
\hline W. Europe & & & & & \\
Austria & 11 & 55 & 79 & 70 & 31 \\
Belgium & 65 & 75 & 54 & 94 & 38 \\
France & 68 & 71 & 43 & 86 & 39 \\
Germany & 35 & 67 & 66 & 65 & 31 \\
UK & 35 & 89 & 66 & 35 & 25 \\
Greece & 60 & 35 & 57 & 112 & na \\
Iceland & NA & NA & NA & NA & NA \\
Ireland & 28 & 70 & 68 & 35 & 43 \\
Italy & 50 & 76 & 70 & 75 & 34 \\
Luxemburg & 40 & 60 & 50 & 70 & NA \\
Netherlands & 38 & 80 & 14 & 53 & 44 \\
Portugal & 63 & 27 & 31 & 104 & 30 \\
Spain & 57 & 51 & 42 & 86 & 19 \\
Switzerland & 34 & 68 & 70 & 58 & 40 \\
\hline
\end{tabular}

\subsection{Research framework and hypotheses}

This study proposes the research framework (Figure 1). As shown in Figure 1, PDI is expected to negatively correlate with decision consistency and decision satisfaction, and to positively correlate with decision consensus. In large power distance societies (China), the people who have small power are easily forced to follow people who have large power, which results in less consistency, less satisfaction, and more consensuses in group decision making. That is, the PDI is a cultural dimension of increasing consistency and satisfaction of Western Europeans, and increasing consensus of Chinese. The IDV is expected to have a negative influence on decision consistency and decision consensus, and a positive influence on decision satisfaction. In the individualistic culture (Western Europe), people tend to freely express their individual opinions resulting in more satisfactory decision making. However, various viewpoints in the individualistic culture are expected to result in less consistency and consensus in decisions. That is, the IDV is a cultural dimension of increasing consistency and consensus of Chinese, and increasing satisfaction of Western Europeans. The MAS is expected to negatively correlate with 
decision satisfaction and decision consensus. In masculine society, the people tend to be more competitive and assertiveness and place less value on relationships and quality of life resulting in less satisfaction, and less consensus of decision making. The correlation between the MAS and decision consistency was thought to be unclear. Because the MASs of China and Western Europe are not significantly different (See Table 1), This study assumed that the influence of the MAS is equal to both cultures. The UAI is expected to positively influence three dependent variables. In strong UAI societies (Western Europe), tolerance for uncertainty and ambiguity is low. Therefore, their decisions are more strict and consistent. Because social norms are well defined in strong UAI societies, decision satisfaction and consensus are easy to obtain. That is, the UAI is a cultural dimension of increasing decision consistency, satisfaction, and consensus of Western Europeans. The LTO is expected to have a positive influence on consistency, and a negative influence on satisfaction and consensus. People in a long-term orientation (China) are more persistent, which positively contribute to consistency of decision making. On the contrary, short-term oriented societies (Western Europe) give more value on the past and present than on the future. Reaching a consensus based on the past or present value is more easy and satisfactory than based on uncertain rewards in the future. That is, the LTO is a cultural dimension of increasing consistency, satisfaction, and consensus in group decision making of Western Europeans.

Based on the frequency of 'Chinese' or 'Western European' in every dimension assuming that all dimensions equally contribute to the dependent variable, three hypotheses have been made as follows.

Hypothesis 1: Decision consistency of Chinese in discussion-involved group decision making is not significantly different from Western Europeans'

Hypothesis 2: Western Europeans have higher satisfaction in discussion-included group decision making than Chinese do.

Hypothesis 3: The perceived degree of decision consensus of Chinese in discussion-involved group decision making is not significantly different from Western Europeans'

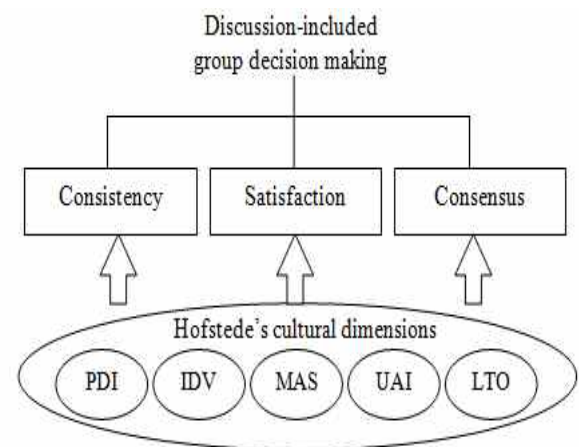

\begin{tabular}{|c|c|c|c|c|c|c|}
\hline & PDI & IDV & MAS & UAI & LTO & Note \\
\hline Higher culture & Chinese & $\begin{array}{l}\text { Westem } \\
\text { European }\end{array}$ & $\begin{array}{l}\text { Chinese }\langle> \\
\text { Westem E. }\end{array}$ & $\begin{array}{l}\text { Westem } \\
\text { European }\end{array}$ & Chinese & See Table 2 \\
\hline Consistency & -(W) & -(C) & $\pm(C \approx W)$ & $+(W)$ & $+(\mathrm{C})$ & $\mathrm{H1}: \mathrm{C} \approx \mathrm{WE}$ \\
\hline Satisfaction & -(W) & $+(W)$ & $-(\mathrm{C} \approx \mathrm{W})$ & $+(W)$ & -(W) & $\mathrm{H} 2: \mathrm{WE}>\mathrm{C}$ \\
\hline Consensus & $+(\mathrm{C})$ & -(C) & $-(\mathrm{C} \approx \mathrm{W})$ & $+(W)$ & $-(W)$ & $\mathrm{H} 3: \mathrm{WE} \approx \mathrm{C}$ \\
\hline
\end{tabular}

$+(-)$ : The cultural dimension and the dependent variable are positively (negatively) correlated. ( \pm : not decided)

$\mathrm{C}(\mathrm{W})$ : Chinese (Western European) culture is more advantageous to increase the condition of the dependent variable and the cultural dimension

Figure 1. Research framework

\section{Methodology}

An experiment was conducted at the Human Factors Laboratory in Tsinghua University in China between March 1st and March 30th, 2011. The experiment is described in detail in the following sections.

\subsection{Experimental design and variables}

A $2 \times 2$ factorial design was used for the experiment. Independent variables included 'culture' and 'discussion involvement' in a group decision making. The 'culture' factor had two levels: (1) Chinese and (2) Western European. The 'discussion involvement' also had two levels: (1) discussion -included and (2) discussion-excluded. The discussion-excluded decision making means that a final group decision is a mathematical integration of individual decisions without discussion. Therefore, a final decision in the discussion-excluded decision making does not need discussion for group 
consensus. On the contrary, subjects classified in the discussion-included decision making had to have discussion to reach a final group decision.

Dependent variables included consistency, satisfaction, and consensus of a decision. Consistency was measured to evaluate objective quality of decision making. A good decision maker has a consistent cognitive process resulting in consistent decision making. In order to measure the decision consistency, critical ratios (CR) from the AHP were used. The smaller the $\mathrm{CR}$ is, the more consistent the decision making is. Four CRs were derived: One value from a group decision after group discussion and three values from three individual decision makers in a group. Satisfaction was measured to compare subjective perceptions on decision results. Three different decision results were given to subjects to make a comparison after the experiment: One set of importance weights obtained from the discussion-included decision making, and two sets of importance weights from the discussion-excluded decision making (Refer to Section: Experimental apparatus). They were asked to rank three sets of importance weights in terms of their satisfaction. As an additional dependent variable to evaluate decision makers' satisfaction on the process of reaching at consensus of a final decision, the degree of consensus was measured. Consensus was measured only in discussion-included decision making because discussion-excluded decision making did not need discussion for consensus.

\subsection{Subjects}

A total of 48 subjects were recruited from students in Tsinghua University in China. Among 48 subjects, 24 were Chinese (16 male and 8 female) and 24 Europeans (22 male and 2 female). The age range is from 21 to 23 for Chinese (22.2 years old on average) and from 20 to 28 for Western Europeans (24.3 years old on average). Western European subjects were from one of five countries - Germany (13), France (7), Ireland (2), UK (1), and Spain (1). Each subject was paid $30 \mathrm{RMB}$ for participation.

\subsection{Experimental apparatus}

The AHP tool was implemented on the 14-inch display-laptop computer (Sony VAIO) generating pair-wise comparison problems (See Figure 2). The goal of the pair-wise comparisons using the AHP tool was to obtain relative importance weights of nine factors affecting their decision making of purchasing a passenger car. The nine factors included brand, price, safety, comfort, model, style, fuel efficiency, service, and performance. A subject or a decision group had to make pair-wise comparisons between two different factors judging relative importance of one factor to another. A subject was asked to choose one of 17 numbers (from 9 at the left to 9 to the right) after a pair-wise comparison (See Figure 2).

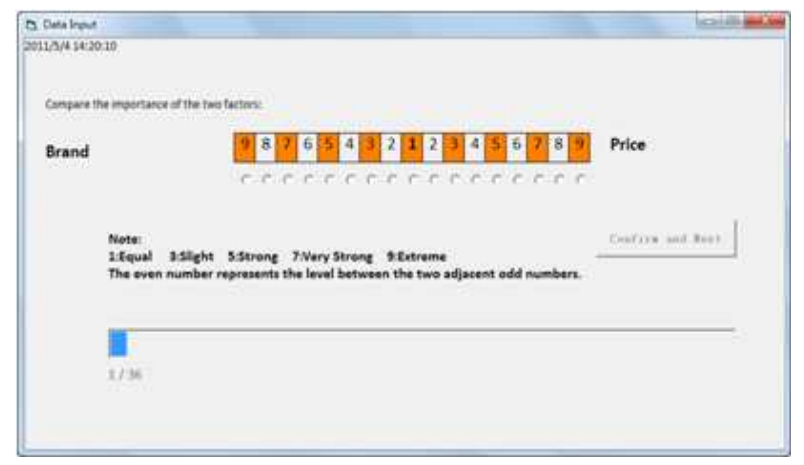

Figure 2. An example display of the AHP tool

Taking 'Brand' and 'Price' for example as shown in Figure 2, one of the left eight numbers (2 to 9) in the horizontal bar should be chosen by clicking the corresponding radio button below the number if the decision maker or the decision group perceives that 'Brand' is more important, and one of the right eight numbers (2 to 9) should be chosen if 'Price' is more important. Choosing 1 means both factors are equally important. The scale from 1 to 9 represents the relative importance of one factor over the other one. The AHP tool was designed to automatically calculate critical ratio (CR) to measure decision consistency of decision makers. The progress of comparisons was also shown in the tool by using the progress bar. Once the subject moved on to the next pair-wise comparison, the AHP tool did not 
allow going back to the previous pair-wise comparison. All of the comparison data were automatically saved into the computer. Questionnaires were used to measure decision satisfaction and consensus, which is described in detail in the following section.

\subsection{Experimental procedure}

Before the experiment, the subjects were given a consent form to confirm their participation in the experiment. After signing it, the subject was given instructions on the AHP tool to use and their task to complete in the experiment. The main experiment was divided into two parts: (1) Discussion-excluded decision making and (2) discussion-included decision making. In discussion-excluded decision making, the group members were not allowed to have discussion to reach a final decision. Each member of the decision group made individual decision making using the AHP tool. Therefore, three data sets from three members were generated in discussion -excluded decision making. On the contrary, in discussion-included decision making, three group members had to discuss to make a final decision. After reaching a decision, one of members inputted the data into the AHP program. So, only one data set was generated in discussion-included decision making. After finishing both discussion-excluded and discussion-included decision making, they were asked to give subjective rankings of satisfaction on the results of their decisions and to rate a degree of consensus after discussion. For satisfaction evaluations, each subject was given three kinds of importance weights (CR-based, average ratingbased, and group ratings-based) automatically calculated by the AHP tool. They were asked to rank three kinds of importance weights in terms of decision satisfactions on the results. The following is a summary on how the three kinds of importance weights were obtained.

(1) CR-based: The importance weights were obtained using the weighted average of three sets of importance weights obtained by three members in a decision group. The $1 / \mathrm{CR}$ value was used as the weight of the decision maker because the higher 1/CR obtained from a higher consistent decision maker can be more reflected to the group decision[2].

(2) Average rating-based: The importance weights were obtained using the geometric means of the three ratings judged by the three individual decision makers.

(3) Group rating-based: The importance weights were obtained using the single ratings by consensus of members after group discussion.

A 5-Likert scale was used to measure a degree of consensus of the discussion. The statement for evaluating consensus was "Our decision group reached consensus after discussion?" The subject was asked to choose one of five numbers for the statement ( 5 for 'totally agree', 4 for 'agree', 3 for 'neutral', 2 for 'disagree', and 1 for 'totally disagree').

\section{Results}

The collected data was analyzed in terms of consistency, satisfaction, and consensus. The detailed results are described in the following sections.

\subsection{Consistency}

As a measure of decision quality, consistency ratios $(\mathrm{CR})$ were used. As shown in Figure 3, the CRs obtained from discussion-included decision making were generally lower than the CRs obtained from in discussion-excluded decision making, which means decisions after discussion were more consistent than individual decisions. The latter result is consistent with previous research[10, 29].

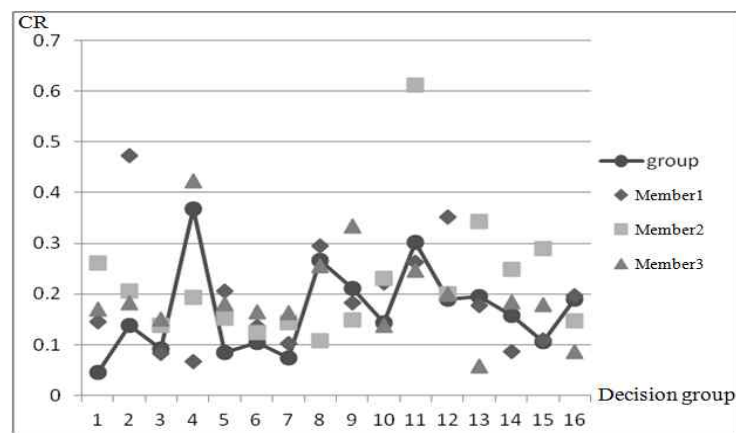

Figure 3. CR values 
As an approach to reach a final decision of a decision group in discussion-excluded decision making, a geometric mean of three scores rated by three members of the group was used for a pair-wise comparison, which is a typical way to reach a group decision. For example, if three members' ratings of the decision group for a pair-wise comparison between 'price' and 'brand' are 5 , 5 , and 7 , their geometric mean, $5.7(=(5 \times 5 \times 7) 1 / 3)$ is inputted as its final rating for this comparison of the group.

Table 2 summarizes average $\mathrm{CR}$ values for both discussion-excluded and discussion-included decisions. The average $\mathrm{CR}$ value in discussion-excluded decisions was based on geometric means of three members' ratings. As shown in the table, average CRs were within the tolerable range of consistency $(\mathrm{CR}<20 \%)$. However, CRs from discussion-included decisions were not in the acceptable range $(<10 \%)$. Chinese on average (14.6\%) were more consistent than Europeans (18.7\%) in the discussion-included decisions. In discussion-excluded decisions, the CRs of Europeans (6.8\%) and Chinese (6.9\%) were almost the same. It means that the decrease of decision consistency of Western Europeans after discussion was than larger that of Chinese.

Table 2. Average CRs

\begin{tabular}{cccc}
\hline & Chinese & $\begin{array}{c}\text { Western } \\
\text { European }\end{array}$ & Total \\
\hline Discussion-excluded & $6.9 \%$ & $6.8 \%$ & $6.8 \%$ \\
Discussion-included & $14.6 \%$ & $18.7 \%$ & $16.6 \%$ \\
Total & $10.8 \%$ & $12.7 \%$ & $11.7 \%$ \\
\hline
\end{tabular}

To investigate if the differences among treatments were significant, two-way ANOVA was conducted. As shown in Table 3, 'culture' and the interaction effect were not significant in consistency of group decisions. Only 'discussion involvement' was significant at $a=0.05$. These analysis results supported the first hypothesis, "Decision consistency of Chinese in discussion-involved group decision making is not significantly different from Western Europeans". However, the cultural dimensions increasing consistency of either culture are thought to be different. As mentioned in Section: Research framework and hypothesis, it is thought that the influence of both IDV and LTO increasing consistency of Chinese and the influence of both PDI and UAI increasing consistency of Western European in group decision making are not significantly different.

Table 3. The ANOVA for the culture $\mathrm{x}$ discussion

\begin{tabular}{cccccc}
\hline $\begin{array}{c}\text { Source of } \\
\text { Variation }\end{array}$ & SS & df & MS & F & $p$-value \\
\hline $\begin{array}{c}\text { Discussion } \\
\text { involvement(D) } \\
\text { Culture(C) }\end{array}$ & 0.07716 & 1 & 0.0772 & 15.716 & $<0.05$ \\
$\begin{array}{c}\text { Interaction } \\
\text { (D x C) }\end{array}$ & 0.00304 & 1 & 0.0030 & 0.6195 & 0.438 \\
$\quad$ Error & 0.13748 & 28 & 0.0049 & & \\
Total & 0.22106 & 31 & & & \\
\hline
\end{tabular}

\subsection{Satisfaction}

Decision satisfaction in light of discussioninvolvement was analyzed. As shown in Table 4, Western Europeans' satisfaction with weights based on group ratings after discussion was higher than Chinese. About $67 \%$ (16 out of 24) of Western European subjects answered that importance weights obtained from discussion-included decisions were most satisfactory, while only $29 \%$ (7 out of 24) Chinese answered so. Instead, Chinese subjects (46\%, 11 out of 24) most preferred average rating-based weights obtained in discussion-excluded decisions

Table 4. Satisfaction ranking comparison

\begin{tabular}{ccccc}
\hline \multirow{2}{*}{ Chinese } & Worst & $\begin{array}{c}\text { Average } \\
\text { rating- } \\
\text { based }\end{array}$ & $\begin{array}{c}\text { Group } \\
\text { rating- } \\
\text { based }\end{array}$ & $\begin{array}{c}\mathrm{CR}^{-} \\
\text {based }\end{array}$ \\
& Medium & 5 & 9 & 10 \\
\multirow{2}{*}{ Western } & Best & 6 & 4 & 7 \\
European & Worst & 6 & 11 & 7 \\
\hline & Medium & 14 & 5 & 5 \\
& Best & 4 & 4 & 16 \\
\hline
\end{tabular}

In order to check if the ranking difference among three kinds of importance weights is significant, the Kruskal-Wallis test was conducted. As shown in Table 5, there was significant difference among 
satisfactions on three kinds of weights for Western Europeans at $a=0.05$. The post-hoc analysis showed the weights obtained after group discussion was significantly preferred to other two kinds of weights (CR-based, Average rating-based). No significant difference was found between CR-based weights and average rating-based weights for Western Europeans. However, Chinese subjects did not show any significant difference in their satisfaction on three kinds of importance weights. These analysis results supported the second hypothesis, "Western Europeans have higher satisfaction in discussion-included group decision making than Chinese do".

Table 5. Kruskal-Wallis test result on satisfaction

\begin{tabular}{lrr}
\hline & Chinese & $\begin{array}{r}\text { Western } \\
\text { European }\end{array}$ \\
\hline Test statistic & 0.7671 & 16.1096 \\
Corrected for ties Ht & 0.8628 & 18.1198 \\
Degree of freedom & 2 & 2 \\
Significance level & $p=0.650$ & $p<0.05$ \\
\hline
\end{tabular}

\subsection{Consensus}

The perceived degree of decision consensus in discussion-included decision making was analyzed. The $\mathrm{t}$-Test was used to evaluate whether two cultures are different or not in terms of a degree of consensus to reach a final decision. As shown in Table 6, average ratings of both cultures were 4 or higher (in 5-Likert scale), which means that discussion to reach a consensus was a satisfactory in both culture. The average consensus rating of Western Europeans (4.125) is slightly higher than that of Chinese (4.0). However, no significant difference was found between Chinese and Western Europeans at $a=0.05$. Therefore, the third hypothesis is also sustained. That is, the perceived degree of group consensus in discussion-included decision making is not different between Europeans and Chinese.
Table 6. t-Test result on consensus

\begin{tabular}{lrr}
\hline & Chinese & $\begin{array}{r}\text { Western } \\
\text { European }\end{array}$ \\
\hline Mean & 4 & 4.125 \\
Variance & 0.0870 & 0.4620 \\
Observations & 24 & 24 \\
Degree of freedom & 46 & \\
$t$ critical (two-tail) & 2.013 & \\
$p$-value & 0.410 & \\
\hline
\end{tabular}

\section{Summary Conclusions and Discussion}

This research showed Sino-Western European cultural differences in group decision making in terms of decision consistency, decision satisfaction, and decision consensus. Group discussion effect was mainly studied to compare Chinese and Western European cultures in group decision making. The research framework was developed on the basis of Hofstede's cultural dimensions to explain the difference of consistency, satisfaction, and consensus between Chinese and Western Europeans. According to Hofstede's research (Hofstede, 2001), China's scores of four dimensions (PDI, IDV, UAI, and LTO) are much different from those of Western Europe. China has much higher scores in the PDI and the LTO than Western Europe while Western Europe generally has much higher IDV and UAI than China. It was assumed that each cultural dimension has different influence on decision consistency, satisfaction, and consensus in group decision making. Based on this assumption, three hypotheses were made and all of three hypotheses are sustained by statistical analyses as follows:

(1) Decision consistency of Chinese in discussion-excluded group decision making was not significantly different from that of Western Europeans. Consistency of Chinese in discussion-included group decision making was on average better than that of Western Europeans. However, The ANOVA test did not show significant difference in decision consistency between two cultures in group decision making, which supports the first hypothesis. It is thought that the collective influences of five cultural dimensions (PDI, IDV, MAS, UAI, and LTO) on both cultures are not significantly different, though individual influences of each cultural dimension on 
both cultures are significantly different.

(2) The second hypothesis is sustained. The Kruskal-Wallis test supported the fact that Western Europeans have higher satisfaction in discussionincluded group decision making than Chinese do. It is thought that four (PDI, IDV, UAI, and LTO) out of five cultural dimensions positively influence decision satisfaction of Western Europeans, while negatively influencing that of Chinese. That is, small power distance, individualism, strong uncertainty avoidance, and short-term orientation of Western Europe are regarded as factors increasing decision satisfaction in discussion-included group decision making. The influence of the MAS on decision satisfaction was neglected because the MAS scores of Chinese and Western Europe are not significantly different.

(3) The t-Test (two-tails) showed that the perceived degree of group consensus of Chinese in discussion-included decision making is not significantly different from that of Western Europeans, which sustains the third hypothesis. It is thought that sum of PDI and IDV influences and sum of UAI and LTO influences on decision consensus are not significantly different.

Some other interesting results were also found. Although decision consistency based on geometric means of individual ratings was significantly better than decision consistency of ratings after group discussion they prefer decision results after discussion. This tendency is more obvious for Western Europeans. For Western Europeans, discussion involvement was more important than decision consistency for their decision satisfaction.

However, discussion involvement for Chinese was not influencing group decision satisfaction as much as Western Europeans. This result accords with an explanation by Mooji[23] that people in the culture of strong uncertainty avoidance are more interested in the process than in the result, and people in the weak uncertainty avoidance cultures are more result oriented than process oriented. Group decisions were more consistent than individual decisions in both Chinese and Western European cultures regardless of discussion involvement. This tendency accords with the previous research maintaining that group judgments tend to be somewhat more accurate than individual judgments[10, 29]. This result showed an importance for group decision making. However, integrated group decisions which mathematically combine individual decisions could greatly enhance decision consistency. In addition to geometric means of individual ratings, a weighted average of individual ratings (e.g. $\mathrm{CR}$ based ratings) can be used to increase decision consistency because higher weights can be multiplied to more consistent decision makers. However, decision accuracy based on arithmetic means of individual ratings was much worse than that of discussion-included group decisions.

Although this research showed cultural differences in group decision making between Chinese and Western Europeans on the basis of the experiment, it has some limitations. Firstly, though Western Europe has a lot in common in culture called as the western culture which is often compared with the eastern culture, Western Europe does not have a unified culture. Besides, the local culture within a country is also diverse[20]. Nevertheless, this research employed the Hofstede's scores to compare Sino-Western European cultures because score differences between China and Western Europe were significantly large from Hofstede's research[11]. Secondly, subjects who participated in the experiment were limited and unbalanced in terms of nationality. Thirdly, this research, did not show which dimension was more influential in group decision making.

Despite aforementioned limitations, this research experimentally investigated the influence of group discussion on group decision making. It also showed significant difference between the two cultures (China and Western Europe), which can be effectively used for cross-cultural management. The research results can be also applied to Korean managerial environments in that the number of foreign employees in Korean companies rapidly increases, and the companies recently face a lot of cross-cultural issues in their management. Because group decision making and discussion, in particular, are very typical managerial activities that require cross-language as well as cross-cultural considerations, they can effectively apply these results for Korean 
managerial environments. In summary, discussion involvement in group decision making is more critically important to Western Europeans than to Chinese for decision satisfaction. Discussion involvement is even more important than decision consistency for Western Europeans satisfaction. That is, depending on the culture involved in group decision making, different managerial techniques can be effectively used to increase decision satisfaction. Discussion-included group decision making techniques such as brainstorming, buzz group analysis, and nominal group technique (NGT) can be more effectively used for Western-Europeans, while discussion-excluded group decision making skills such as delphi technique, mathematical models can be alternatively used for Chinese[17].

\section{References}

[1] Arrow, KJ. (1963), "Social choice and individual values." (2nd ed.), New York: Wiley.

[2] Byun, D.H. (2000), "The AHP approach for selecting an automobile purchase model." Information \& Management, 38:289-297.

[3] Carlo, G., Roesch, S.C., Knight, G.P., \& Koller, S.H. (2001), "Between- or within-culture variation? Culture group as a moderator of the relations between individual differences and resource allocation preferences." Applied Developmental Psychology, 22:559-579.

[4] Carpenter, M., Bauer, T., \& Erdogan, B. (2009), "Principles of management. Irvington." New York: Flat World Knowledge, Inc.

[5] Chen, C.J., \& Huang, CC. (2004), "A multiple criteria evaluation of high-tech industries for the science-based industrial park in Taiwan." Information \& Management, 41(7):839-851.

[6] Condon, E., Golden, B., \& Wasil E. (2003), "Visualizing group decisions in the analytic hierarchy process." Computers and Operations Research, 30:1435-1445.

[7] Forgionne, G.A., \& Kohli, R. (2001), "A multiple criteria assessment of decision technology system journal quality." Information \& Management, 38(7):421-435.
[8] Gunnarsson, M. (2010), "Group decision making.". Frederick, MD: Verlag.

[9] Harries, C., Yaniv, I., \& Harvey, N. (2004), "Combining advice: the weight of a dissenting opinion in the consensus." Journal of Behavioral Decision Making, 17(5):333-348.

[10] Hastie, R. (1986), "Experimental evidence on group accuracy." In B. Grofman \& G. Owen (Eds.), Decision research (Vol. 2, pp. 129-157). Greenwich, CT: JAI Press.

[11] Hofstede, G. (2001), "Culture's consequences: Comparing values, behaviors," Institutions and Organizations Across Nations (2nd ed.). Thousand Oaks, CA: SAGE Publications.

[12] Janis, I.L. (1972), "Victims of groupthink." Boston: Houghton Mifflin.

[13] Kamau, C. \& Harorimana, D. (2008), "Does knowledge sharing and withholding of information in organizational committees affect quality of group decision making?" In D. Harorimana, \& D. Watkins (Eds.), 9th European Conference on Knowledge Management (pp. 341-348). UK: Academic Publishing Limited.

[14] Kwok, R.C.W., Ma, J., \& Zhou D.N. (2002), "Improving group decision making: a fuzzy GSS approach," IEEE Transactions on Systems, Man, and Cybernetics, Part C: Applications and Reviews, 32(1):54-63.

[15] Lai, V.S., Trueblood, R.P., \& Wong, B.K. (1999), "Software selection: a case study of the application of the analytical hierarchical process to the selection of a multimedia authoring system." Information \& Management, 36:221-232.

[16] Larson, J.R., Sargis, E.G., \& Bauman, C.W. (2004), "Shared knowledge and subgroup influence during decision-making discussions." Journal of Behavioral Decision Making, 17(4):245-262.

[17] Lehto, M. R., \& Buck, J. R. (2008), "Introduction to human factors and ergonomics for engineers." New York: Taylor \& Francis.

[18] Liberatore, M.J., \& Nydick, R.L. (1997), "Group decision making in higher education using the analytic hierarchy process." Research in Higher Education, 38:593-614.

[19] Lunenburg, F. C. (2010), "Group decision making: The potential for groupthink." 
International Journal of Management, Business, and Administration, 13(1):1-6.

[20] McSweeney, B. (2002), "Hofstede's model of national cultural differences and their consequences: a triumph of faith - a failure of analysis." Human Relations, 55(1):89 - 118.

[21] Melon, M.G., Beltran, P.A., \& Cruz, M.C.G. (2008), "An AHP-based evaluation procedure for innovative educational projects: A face-to-face vs. computer-mediated case study." Omega, 36:754-765.

[22] Miner, F.C. (1984), "Group versus individual decision making: An investigation of performance measures, decision strategies, and process losses/gains." Organizational Behavior and Human Performance, 33:112 - 124.

[23] Mooji, M.D. (2010), "Consumer behavior and culture: consequences for global marketing and advertising," (2nd ed.). Thousand Oaks, California: Sage Publications, Inc.

[24] Moscovici, S. (1985), Social influence and conformity. In E. Aronson \& G. Lindsay (Eds.), Handbook of social psychology (Vol. 2, pp. 347-412). Reading, MA: Addison-Wesley.

[25] Quaddus, M.A., \& Tung, L.L. (2002), "Explaining cultural differences in decision conferencing." Communications of the ACM, 45(8):93-98.

[26] Saaty, T.L., \& Vargas, L. G. (2003), "Dispersion of group judgments: the geometric expected value operator." In B. L. Golden, S. Raghavan, \& E. A. Wasil (Eds.), The Next Wave in Computing, Optimization, and Decision Technologies (pp. 385-396). US: Springer.

[27] Saaty, T.L. \& Kearns, K. P. (1985), "Analytical planning: the organization of system.". Oxford: Pergamon Press.

[28] Sniezek, J.A. (1989), "An examination of group process in judgmental forecasting." International Journal of Forecasting, 5, $171-178$.

[29] Sniezek, J.A, \& Henry, R.A (1989), "Accuracy and confidence in group judgment." Organizational Behavior and Human Decision Processes, 43:1-28.

[30] Tam, M.C.Y., \& Tummala V.M.R. (2001), "An application of the AHP in vendor selection of a telecommunications system." Omega, 29:171-182.

[31] Yaniv, I., \& Choshen-Hiller, S. (2011), "Exploiting the wisdom of others to make better decisions: suspending judgment reduces egocentrism and increase accuracy." Journal of Behavioral Decision Making, published online. DOI: 10.1002/bdm740.

[32] Zhang, D.D., Lowry, P.B., Zhou, L., \& Fu, X.L. (2007), "The impact of individualismcollectivism, social presence, and group diversity on group decision making under majority infl uence." Journal of Management Information System, 23(4):53- 80.

[33] Zhou, S.B. (2008), "Cultural differences between China and Western Europe." Special Zone Economy, 8, 28-30.

\section{Author's biography:}

Pilsung Choe

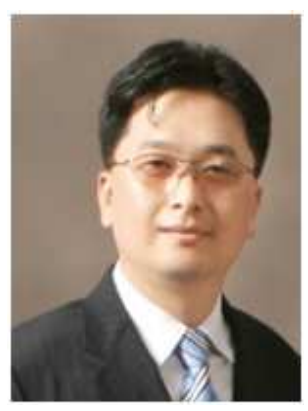

Dr. Pilsung Choe received his $\mathrm{BS}, \mathrm{MS}$, and $\mathrm{PhD}$ degrees from Hanyang University, Postech, and Purdue University, respectively. He currently serves as an associate professor in the Department of Industrial Engineering at Tsinghua University. His research area includes user-centered design, user and customer experience, and information processing and decision making.

Wen Zhu

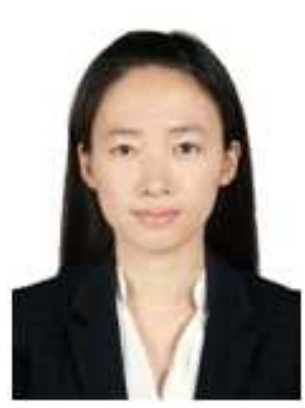

Ms. Wen Zhu received her BS degree from the Department of Industrial Engineering, Tsinghua University. She is a master student in the Department of Management and Science, School of Economics and Management, Tsinghua University. 